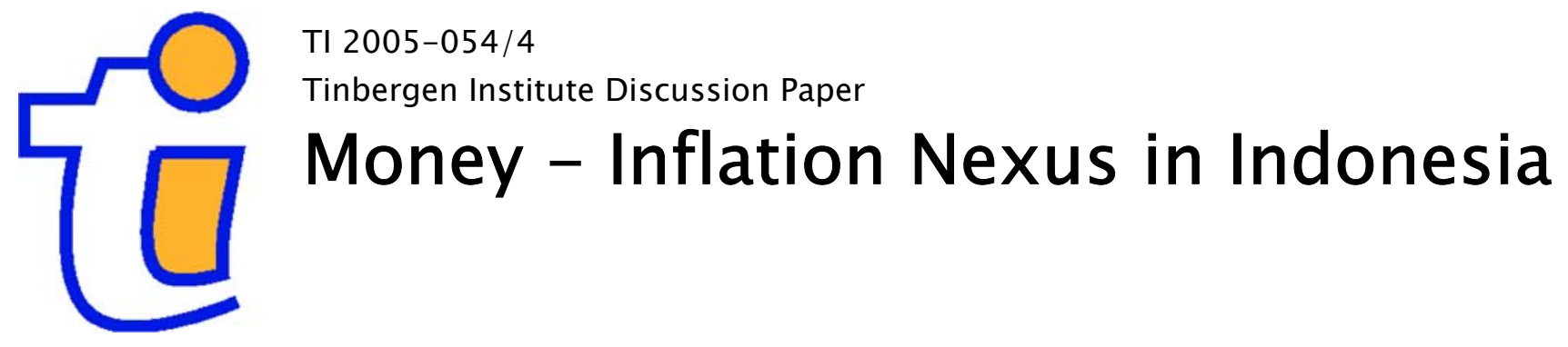

Reza Anglingkusumo

Vrije Universiteit Amsterdam, and Bank Indonesia - Jakarta. 


\section{Tinbergen Institute}

The Tinbergen Institute is the institute for economic research of the Erasmus Universiteit Rotterdam, Universiteit van Amsterdam, and Vrije Universiteit Amsterdam.

Tinbergen Institute Amsterdam

Roetersstraat 31

1018 WB Amsterdam

The Netherlands

Tel.: $\quad+31(0) 205513500$

Fax: $\quad+31(0) 205513555$

Tinbergen Institute Rotterdam

Burg. Oudlaan 50

3062 PA Rotterdam

The Netherlands

Tel.: $\quad+31(0) 104088900$

Fax: $\quad+31(0) 104089031$

Please send questions and/or remarks of nonscientific nature to driessen@tinbergen.nl.

Most TI discussion papers can be downloaded at http://www.tinbergen.nl. 


\title{
Money - Inflation Nexus in Indonesia: Evidence From a P-Star Analysis
}

\author{
Reza Anglingkusumo ${ }^{1}$ \\ (2005b)
}

\begin{abstract}
In this paper the effect of excess narrow money (M1) on CPI inflation in Indonesia before, during, and after the Asian crisis is empirically examined. The standard model for the monetary analysis of inflation, i.e. the P-Star model by Hallman-Porter-Small (1991), is applied and tested empirically using quarterly Indonesian data between 1981 and 2002. The empirical model is a Markov switching error correction model. The results show that the two regime $\mathrm{P}$-star model, in terms of excess M1, tracks the long run dynamics of CPI inflation in Indonesia remarkably well. Hence, there is an empirical support for the assertion that long run CPI inflation in Indonesia is a monetary phenomenon. In addition, there is evidence of a co-breaking relationship between excess M1 and consumer prices in Indonesia during the Asian crisis.
\end{abstract}

JEL classifications: E31, C12

Key Words: inflation, monetary model, structural break, regime switching error correction model, co-breaking, Asian crisis, Indonesia

\footnotetext{
${ }^{1}$ I thank without implicating prof. dr. A.F.P. Bakker of De Nederlandsche Bank - Amsterdam and dr. Marius Ooms of the Vrije Universiteit - Amsterdam for their comments and input. All remaining errors are mine. Email: ranglingkusumo@,imf.org
} 


\section{Introduction}

Since the float of the rupiah and the Asian crisis in 1997, understanding the sources of inflation in Indonesia has been at the crux of Bank Indonesia (BI)'s research agenda. This is portrayed for instance by the trend towards a more rigorous and comprehensive inflation analysis within BI's own annual, quarterly, and monthly reports. In part, such a trend is conditioned by a stipulation within the newly enacted Central Bank Act no. 23/1999 that requires BI to periodically publish inflation reports outlining the development and the prospects of inflation. Yet, it seems that there are only a few independently published empirical analyses on the sources of the aggregate consumer price inflation in Indonesia.

Taylor (2000) in his post conference speech at BI suggested the presence of a strong link between the growth of the base money aggregate and the consumer price inflation since the Asian crisis. McLeod $(2002,2003)$ echoes this observation and suggests that the money-inflation nexus had been present even before the Asian crisis ${ }^{2}$.

This paper is intended to contribute further to the analysis on money-inflation nexus in Indonesia. To serve this aim, we employ a variant of the monetarist type analysis of inflation, namely the P-star model of inflation as developed by Hallman et al (1991). Such an analysis complements BI's New Keynesian model of inflation that, by its nature, is designed to analyze only the short-term sources of inflation (see Hutabarat et al (2000)). The P-star analysis, on the other hand, due to its hereditary link with hypotheses developed by the late 19th and early $20^{\text {th }}$ century classical economists (i.e. David Hume and Irving Fisher), is a long run analysis of inflation (Humphrey, 1989).

Many authors have used the P-star model with considerable success to explain the long run dynamics of inflation in developed countries. Some instances are the works by Kool and Tatom (1994), Trecroci and Vega (2000), Herwartz and Reimers (2001), and Gerlach and Svensson (2003). For the developing countries, Nachane and Lakshmi (2002) have fruitfully applied several variants of the model in India.

As to the empirical methodology, we rely on the two regime Markov-switching vector error correction model (MS-VECM) developed by Krolzig (1996, 1997, 1998). In a nutshell this methodology allows non-linearity in the vector error correction model. This nonlinearity is modeled by unobservable Markovian random switching regimes as put forward by Hamilton $(1989,1990)$. The methodological preference for switching regimes is forced upon us by the observation that the monetary crisis period in Indonesia in the late 1990s induced breaks in the data generating process of the country's aggregated macroeconomic variables, e.g. the consumer price index (CPI), monetary aggregates, and real output. As a consequence, any econometric model to support an empirical study on the issue of inflation in Indonesia must take into account such regime shifts. Hence, the MS-VECM methodology has an appealing advantage. With this methodological choice, this paper adds fresh results to the existing literature on the money-inflation nexus, in particular for the specific case of the Indonesian economy.

\footnotetext{
${ }^{2}$ See McLeod (1997) for the pre-crisis analysis on the money-inflation nexus in Indonesia.
} 
The rest of this paper is organized into the following sections. Section 2 briefly outlines the P-star analysis of inflation. Section 3 presents the research framework for estimating the regime switching P-Star model of the Indonesian consumers' price inflation. Section 4 discusses the empirical results. Section 5 concludes this paper.

\section{The P-Star Analysis of Inflation}

Despite the fact that nothing is entirely new in the P-Star analysis of inflation, the reformulation of the classical quantity equation in terms of the P-Star equation as done in Hallman et al (1991) has stimulated a bulk of empirical studies to re-verify the long standing claim of the monetarist's school of thought that inflation is always and everywhere a monetary phenomenon, in the long run.

The P-Star analysis starts with the following classical quantity equation:

$$
m_{t}+v_{t}=p_{t}+y_{t}
$$

where $m_{t}, v_{t}, p_{t}$, and $y_{t}$, are the logs of nominal money, velocity, price level, and real output, respectively, and $t$ is the time subscript. In line with the classical quantity theorists, assumptions are made that the logs of real output and velocity are equal to their equilibrium values. Using these assumptions, equation (1) can be rewritten as the following "P-star equation", where * denotes the equilibrium values:

$$
p^{*}{ }_{t}=m_{t}-y^{*}+v^{*}{ }_{t}
$$

This equation simply states that the equilibrium price level is the price level that is consistent with the current nominal money stock evaluated at the equilibrium levels of real output and velocity ${ }^{3}$. Combining (1) and (2), defining the inflation rate $\pi_{t}$ as $p_{t}-p_{t-1}$, and incorporating the inertial component (lag) of the inflation rate as a measure of either the degree of inflation persistence or the degree of agents' adaptive expectations, the inflation dynamics in a stochastic environment can be expressed by the following single equation error correction representation ${ }^{4}$ :

$$
\pi_{t}=\left(1-\gamma_{0}\right) \pi_{t-1}+\gamma_{1} \Delta p_{t-1}^{*}-\gamma_{2}\left(p_{t-1}-p_{t-1}^{*}\right)+\varepsilon_{t} ; \varepsilon_{t} \sim N I I D
$$

where $\Delta p^{*}{ }_{t-1}=p^{*}{ }_{t} p^{*}{ }_{t-1}$ and $0<\gamma_{0}<1$. If $p^{*}{ }_{t}$ and therefore $m_{t}-y^{*}{ }_{t}+v^{*}{ }_{t}$ is $I(1)$ and exogenous in some sense, equation (3) explicitly suggests that in the long run $\left(p_{t}-p_{t}{ }^{*}\right)$ is stationary, i.e. $p_{t}$ and $p^{*}{ }_{t}$ are cointegrated, $C I(1,1)$, in the sense of Engle-Granger (1987). By the Granger representation theorem, there is an adjustment coefficient $\gamma_{2}$, where $0<\gamma_{2}<1$, which is guiding the long run dynamics of $p_{t}$ so that $\left(p_{t}-p_{t}\right)$ is mean reverting and stationary $I(0)$ variable and $\pi_{t}$ is also $I(0)$.

In equation (3) inflation is determined by lagged inflation (inertia), by lagged changes in equilibrium price ("excess money"), and by the lagged "price gap", that is the deviation of the price level from its equilibrium value. Hence, by virtue of the "price gap" effect, if the current price is above/below its equilibrium value, then the future inflation should decline/increase to keep the price level move in unison with its long run equilibrium.

\footnotetext{
${ }^{3}$ Or simply put, $p^{*}$ is the proxy measure of "excess money".

4 An alternative expression is to model inflation as the result of both the deviations of velocity from its equilibrium value and real output from its potential. We do not pursue this alternative expression in this paper.
} 
Obtaining the values for $v^{*}$ and $y_{t}{ }^{*}$ is at the backbone of the P-Star analysis. Herwatz and Reimers (2001) provide some simple guidelines for deriving $v_{t}{ }_{t}$. First of all, assume that a real money demand equation representing the long run monetary equilibrium condition can be written as:

$$
m_{t}-p_{t}=\eta_{0}+\eta_{1} y^{*}+z_{t}
$$

where $\eta_{0}$ is a constant, $\eta_{1}$ is the long run income elasticity of money, and $z_{t}$ is a stationary component of real money. Combining equations (1) and (4) and solving for $v_{t}$ yields:

$$
v_{t}=-\eta_{0}+\left(1-\eta_{1}\right) y^{*}-z_{t}
$$

Hence the equilibrium velocity can be defined as the velocity that is evaluated when the real output $y_{t}$ is at $y^{*}{ }_{t}$ (potential / equilibrium output) and $z_{t}=0$ such that:

$$
v^{*}=v_{0}+\left(1-\eta_{1}\right) y^{*}{ }_{t}
$$

where $v_{0}=-\eta_{0}$. If $\eta_{1}>1$, then $v^{*}$ will be the negative of $y^{*}{ }_{t}$. On the other hand, if $\eta_{1}=1$, then the equilibrium velocity collapses to a constant.

It directly follows from equation (6a) that $y_{t}{ }^{*}$ must be provided to compute $v^{*}$. In the presence of a reliable data on potential output, the variable $y_{t}^{*}$ becomes directly observable ${ }^{5}$. However in the absence of potential output data, then $y_{t}^{*}$ must be estimated independently. Several time series methodologies are available to estimate $y_{t}{ }^{*}$, i.e. the underlying trend in $y_{t}$, such as the Hodrick-Prescott (1997) filter, unobservable component methods, and band-pass filtering techniques. For reasons that will be explained later we argue that in Indonesia $y_{t}{ }^{*}$ can be satisfactorily approximated by $c_{t}$, namely the $\log$ real private household consumption spending. Hence, the following relationship is assumed in Indonesia:

$$
y_{t}^{*}=c_{t}
$$

With the measures of $v^{*}$ and $y_{t}{ }^{*}$ in hand, equation (3) can be empirically tested. The simple yet plausible approach towards the modeling of the money-inflation nexus described above, has brought a new vigor to the monetarist's explanation of inflation, provided a framework for empirical verifications, and encouraged our study in this paper.

\section{The Framework for the Empirical Regime Switching P-Star for Indonesia}

\subsection{The Methodology}

This paper focuses on equation (3) as described in Section 2. This linear equation assumes the absence of any structural break in the data generating process of inflation, hence $\pi_{t}$ is $I(0)$. Figure 1 suggests that the quarterly changes in CPI inflation in Indonesia can be seen to be mean reverting with fixed mean only if the mean is adjusted upward roughly around 1998. Hence, a process with time varying parameters is guiding the behavior of inflation in Indonesia in this period.

\footnotetext{
${ }^{5}$ We assume that the notion of potential real output is equivalent to the equilibrium real output. Hence these two concepts are used interchangeably.
} 
Figure 1. Quarterly CPI Inflation in Indonesia (Q1/1981 - Q4/2002)

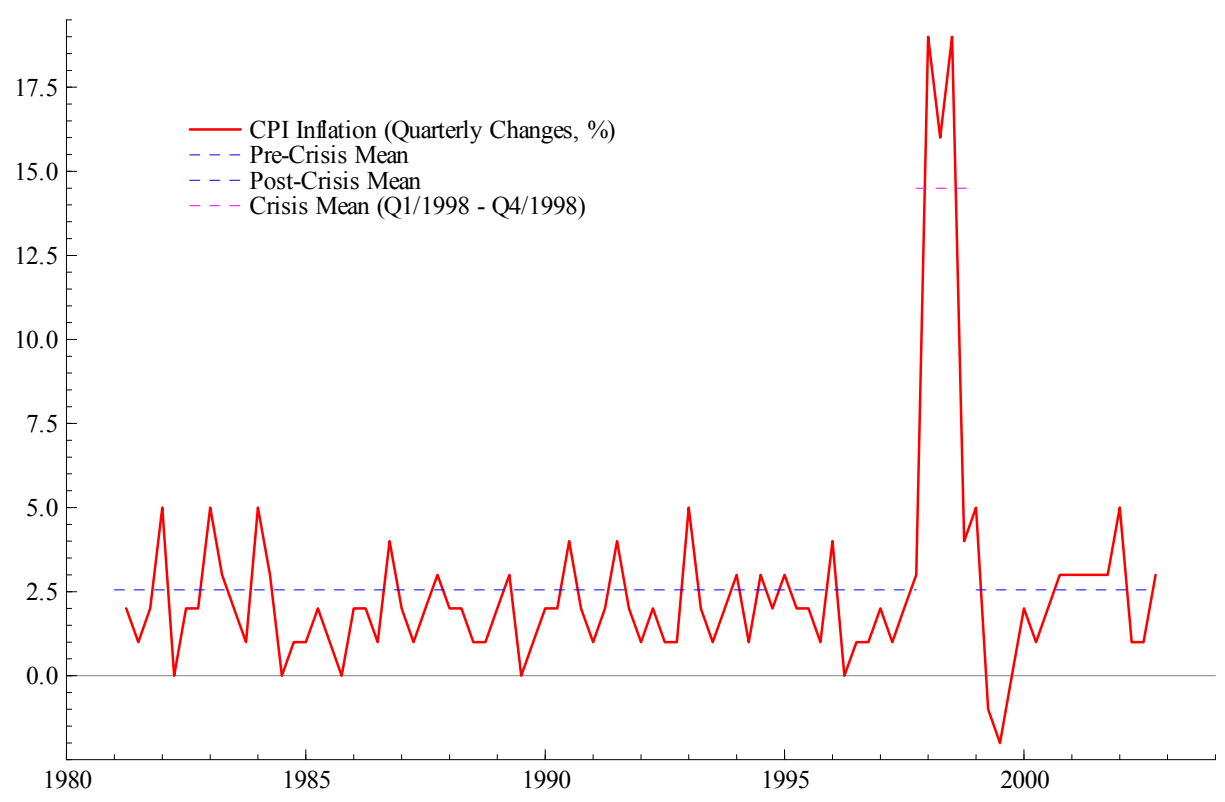

To obtain the (non-linear) breaks in equation (3) we follow the two steps MS-VECM methodology as outlined and implemented in Krolzig $(1996,1997,1998)$. Below is a brief description of the methodology.

Consider the following MS-VAR, that is a Markov-Switching VAR where some of the parameters are governed by Markovian regime shifts:

$$
q_{t}=v\left(s_{t}\right)+\sum_{i=1}^{p} B_{i} q_{t-i}+\varepsilon_{t} ; \quad \varepsilon_{t} \sim \operatorname{NID}(0, \Sigma)
$$

where $q_{t}$ is an $n$-dimensional vector of endogenous variables, $v\left(s_{t}\right)$ is an $n$-dimensional column vector of state dependent intercepts, the $B_{i}$ are $n \times n$ parameter matrices, and $\varepsilon_{t}$ is an $n$-dimensional vector of Gaussian errors with covariance matrix $\Sigma$. This MS-VAR allows for regime shifts depending on state variable $s_{t}$ in the intercept term. The regimes are generated by an ergodic Markov chain defined by the following transition probabilities:

$$
p_{i j}=\operatorname{Pr}\left(s_{t+1}=j \mid s_{t}=i\right), \quad \Sigma_{j} p_{i j}=1, \quad \forall i, j \in\{1, \ldots, m\}
$$

where $m$ is the number of regimes. If the variables in $q_{t}$ are cointegrated, then there are up to $n-1$ linearly independent cointegrating relationships in the MS-VAR system, and by an adjusted Granger representation theorem there is a vector error correction representation of equation (7), namely:

$$
\Delta q_{t}=v\left(s_{t}\right)+\sum_{i=1}^{p-1} \Gamma_{i} \Delta q_{t-i}+\Pi q_{t-1}+\varepsilon_{t} ; \quad \varepsilon_{t} \sim N I D(0, \Sigma)
$$

where $\Gamma_{i}$ are matrices of short run parameters and $\Pi=-\left(I-B_{1}-\ldots-B_{p}\right)$ is a reduced rank long run impact matrix with rank $r$ indicating the number of cointegrating relationships. Following the convention in the literature on vector error correction models (VECM), the matrix $\Pi$ in equation (9) can be decomposed into the matrix of loading coefficients, $\alpha$, with dimension $n \times r$, and the matrix of cointegrating coefficients, $\beta$, with dimension $r \times n$. As such, equation (9) can be rewritten as: 


$$
\Delta q_{t}=v\left(s_{t}\right)+\sum_{i=1}^{p-1} \Gamma_{i} \Delta q_{t-i}+\alpha\left(\beta^{\prime} q_{t-1}\right)+\varepsilon_{t} ; \quad \varepsilon_{t} \sim N I D(0, \Sigma)
$$

Relaxing the assumption that only the intercepts are subject to regime shifts variable $s_{t}$, we obtain a more general specification of equation (10) where in addition to the intercepts, the adjustment coefficients (short and long run), and the variances in equation (10) are also subject to $s_{t}$, such as written in the following equation:

$$
\Delta q_{t}=v\left(s_{t}\right)+\sum_{i=1}^{p-1} \Gamma_{i}\left(s_{t}\right) \Delta q_{t-i}+\alpha\left(s_{t}\right)\left(\beta^{\prime} q_{t-1}\right)+\varepsilon_{t} ; \varepsilon_{t} \sim N I D\left(0, \Sigma\left(s_{t}\right)\right)
$$

In this specification $v, \Gamma_{i}$, and $\alpha$ will be governed by $m$ stochastically generated regimes as defined in equation (8).

Using equation (11), if we assume the rank of $\Pi=1$ and $p=2$ for simplicity, then two non-linear instances of equation (3) are possible, namely:

$\Delta p_{t}=v_{1}\left(s_{t}\right)+\Gamma_{11} \Delta p_{t-1}+\Gamma_{12} \Delta p_{t-1}^{*}+\alpha_{1}\left(p_{t-1}-p^{*}{ }_{t-1}\right)+\varepsilon_{1 t} ; \varepsilon_{1 t} \sim N I D\left(0, \Sigma_{1}\left(s_{t}\right)\right)$

$\Delta p_{t}=v_{2}\left(s_{t}\right)+\Gamma_{21}\left(s_{t}\right) \Delta p_{t-1}+\Gamma_{22}\left(s_{t}\right) \Delta p_{t-1}+\alpha_{2}\left(s_{t}\right)\left(p_{t-1}-p_{t-1}\right)+\varepsilon_{2 t} ; \varepsilon_{2 t} \sim \operatorname{NID}\left(0, \Sigma_{2}\left(s_{t}\right)\right)(12 b)$

In equation (12a), only the intercept (I) and the heteroskedasticity $(\mathrm{H})$ components are functions of the Markovian regime switching process, $s_{t}$. Meanwhile in equation (12b), the coefficients of the short and long run adjustments (A) are also subject to Markovian shifts. Accordingly equation (12a) can be denoted as $M S I H(m)-E C M(k)$, and equation (12b) as $\operatorname{MSIAH}(m)-E C M(k)$, where $k=p-1$. Theoretically, as with the coefficients in the linear equation (3), coefficients $\Gamma_{11}, \Gamma_{12}, \Gamma_{21}$ and $\Gamma_{22}$ in equation (12a) and (12b) should be larger than 0 , and both $\alpha_{1}$ and $\alpha_{2}$ should be within $[-1,0]$.

The estimation of equations (12a) and (12b) above can be done using the two-step maximum likelihood procedures suggested by Krolzig (1997, p. 297 - 328). In the first step, the rank of $\Pi$ is tested using the conventional full-information maximum likelihood technique developed by Johansen $(1988,1991,1995)$. For an analysis in the presence of possible trend breaks, see Johansen-Mosconi-Nielsen (2000) and an application in Anglingkusumo (2005a). In the second step, maximum likelihood estimation for the parameters in the MS-VECM is performed using the EM algorithm as suggested by Hamilton (1990) and extended in Krolzig (1997). This procedure will yield both the parameter values and the regime probabilities of the MS-VECM. There are two types of regime probabilities that will be obtained via the EM algorithm, i.e. the filtered and the smoothed regime probabilities. The former is the optimal estimate of the unobservable state variable at time $t$ conditional upon the information set up to time $t$, and the latter is the optimal estimate conditional upon the full sample information. Krolzig (1998) provides a computerized procedure for performing the EM algorithm and estimating the MS-VECM ${ }^{6}$.

\subsection{The Data}

We use quarterly data of $m_{t}, p_{t}$, and $c_{t}$ from Q1/1981 until Q4/2002. We proxy $m_{t}, p_{t}$, and $c_{t}$ with the log nominal narrow money (M1), the log consumers' price index (CPI), and the $\log$ of real private household consumption spending, respectively. The original

\footnotetext{
${ }^{6}$ For examples on the application of the MS-VECM framework see inter alia Clarida, et al (2003), Tillman (2003), Krolzig, et al (2002), and Sarno, et al (2002).
} 
frequencies of $m_{t}$ and $p_{t}$ are monthly. We construct the quarterly series by taking 3 month moving averages. This data transformation seems to substantially eliminate the presence of seasonal components in the two series. Meanwhile, the original frequency of the $c_{t}$ data is quarterly. There are strong seasonal components in the original $c_{t}$ data and therefore a Census X-12 seasonal correction without trading day adjustments is performed ${ }^{7}$.

Figure 2. The Time Series Plots of $m_{t}, p_{t}$ and $c_{t}$ (in logarithms, intercepts adjusted using the intercept of $c_{t}$ as the benchmark)

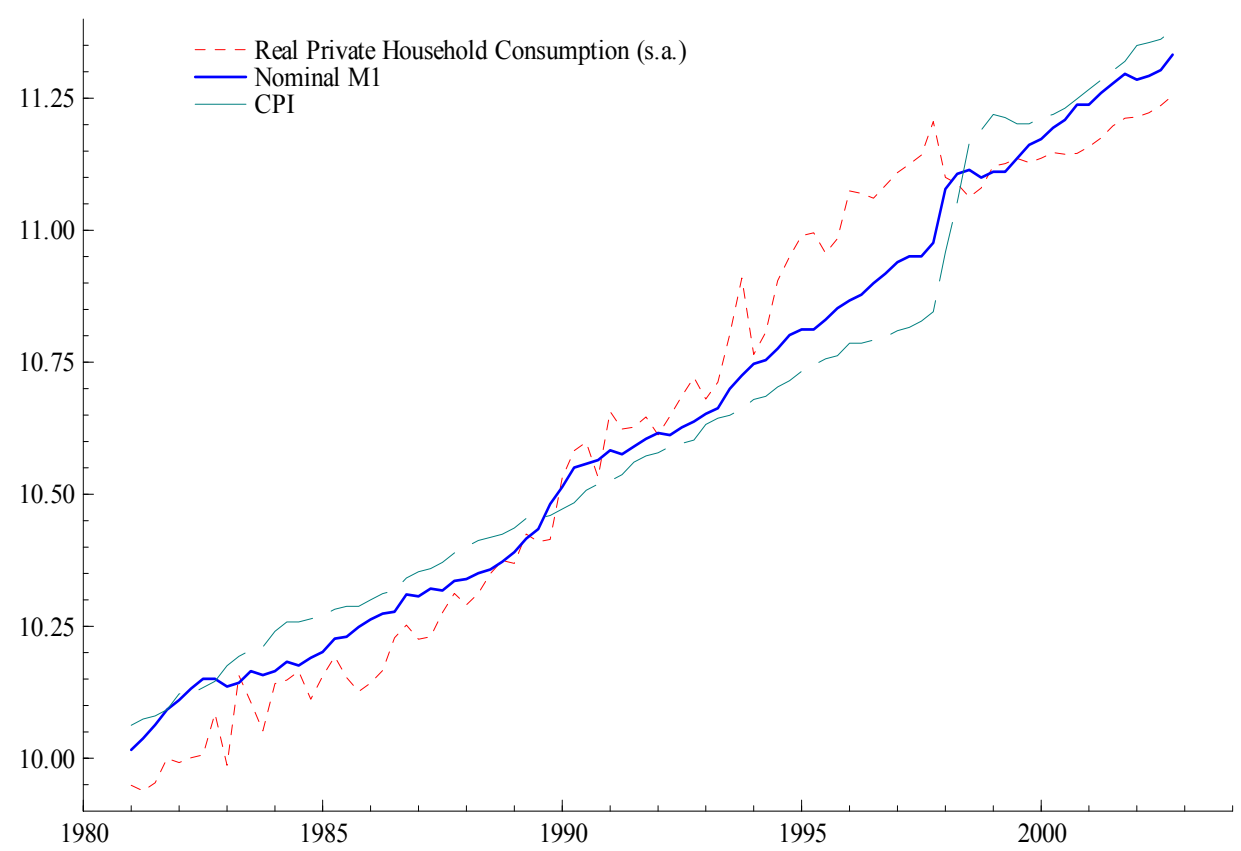

Note: The intercepts of $m_{t}$ and $p_{t}$ are adjusted using the intercept of $c_{t}$ as the benchmark.

As mentioned in Section 2, $y_{t}{ }^{*}$ is approximated by the log real private household consumption, $c_{t}$. The following reasons motivate such an approximation. First of all, there are no uniform estimates of potential output in Indonesia. This serves as a natural constraint for our study. Second, we argue that the growth in the log real private household consumption has been the main component driving the growth of log real GDP in Indonesia since $1980^{8}$. During the height of the monetary crisis in $1998, c_{t}$ was the only component of real GDP $\left(y_{t}\right)$ that exhibited only a mild slump compared to the other components, which showed much deeper troughs. Since the notion of potential output closely resembles the permanent (persistent) part of real income (output), the characteristic behavior of $c_{t}$ in Indonesia mimics the persistence that can be found in a typical potential long run income (output) series. Hence, the use of $c_{t}$ as an approximation of $y_{t}{ }^{*}$, although imperfect, is warranted. Figure 2 provides time series plots of $m_{t}, p_{t}$, and $c_{t}$.

\footnotetext{
${ }^{7}$ In E-Views 4.1. with multiplicative seasonal for $c_{t}$.

${ }^{8}$ With a constant ratio of consumption / GDP of approximately 0.6.
} 


\section{Empirical Results}

\subsection{Quarterly Inflation Models}

Before starting with Step 1 of the two step procedure outlined in Krolzig (1997, p. 297 - 328) we need to examine preconditions for a P-Star interpretation of the results. The estimation of equations (12a) and (12b) in section 3 requires that there exists a cointegration relationship between $p_{t}$ and $p^{*}$. However, from section 2 we know that prior to analyzing the long run relationship, $p^{*}{ }_{t}$ needs to be constructed. Since we have assumed that $y^{*}{ }_{t}$ can be approximated by $c_{t}$, then it is sufficient for the construction of $p^{*}{ }_{t}$ that the following requirements hold:

[H1]. There exists a monetary equilibrium condition (MEC) in the form of equation (4). The preconditions for the existence of such an MEC are:

[H1A] Equation (4) is long run homogeneous in $p_{t}$.

[H1B] There is a trendless cointegration relationship linking the variables in the vector $W_{t}=\left[m_{t}, p_{t}, c_{t}\right]$, such that they are $C I(1,1)_{r=1}$ without deterministic trend in the cointegrating vector ${ }^{9}$.

If $\mathrm{H} 1 \mathrm{~A}$ and $\mathrm{H} 1 \mathrm{~B}$ hold, then $W_{t}$ can be reparameterised into $W_{t}^{*}=\left[m_{t}-p_{t}, c_{t}\right]$.

[H1C] There is a trendless cointegration relationship in the vector $W_{t}^{*}$ such that $\left(m_{t}\right.$ $\left.p_{t}\right)$ and $c_{t}$ are $C I(1,1)_{r=1}$ where $c_{t}$ serves as a weakly exogenous variable for the estimation of the cointegrating vector ${ }^{10}$.

[H2]. There exists a stationary equilibrium velocity, $v^{*}$. As shown by equation (6a), this requires condition $[\mathrm{H} 1 \mathrm{C}]$ holds and the long run elasticity of $m_{t}-p_{t}$ with respect to $c_{t}$ equals 1 in the cointegrating vector for $W_{t}^{*}$.

If [H1] and [H2] are satisfied, then $p^{*}$ can be constructed using equation (2). For both equations (12a) and (12b) to become operational, however, several more requirements are needed, namely:

[H3]. There exists a cointegrating relationship such that $p_{t}$ and $p^{*}{ }_{t}$ in $Z_{t}=\left[p_{t}, p_{t}{ }_{t}\right]$ are $C I(1,1)_{r=1}$ without a deterministic trend in the cointegrating vector.

[H4]. The variable $p^{*}{ }_{t}$ in $Z_{t}$ is weakly exogenous for the estimation of the cointegrating vector.

Requirements $\mathrm{H} 1$ and $\mathrm{H} 2$ were already examined in Anglingkusumo (2005a). We summarize the main findings in Step 1A below. We investigate requirements H3 and H4 under Step 1B. In Steps 1A and 1B we model the crisis period by dummy variables. Step 2 then examines Markov-Switching models to capture changes in the P-Star relationship. We conclude the empirical section with an analysis of $\Delta_{4} p_{t}$, i.e. annual (year on year) inflation.

\footnotetext{
${ }^{9} C I(1,1)_{r=1}$ denotes the presence of cointegration among $I(1)$ variables with the rank of matrix $\Pi=1$.

${ }^{10}$ For a review on the definition, properties, and implications of the notion of weak exogeneity in the modeling of a cointegrated system see Boswijk (1992), Johansen (1992), Ericsson, Hendry, and Mizon (1998), and Hendry - Juselius (2000). Some concise reviews are available in Favero (2001) and Harris-Sollis (2003)
} 


\section{Step 1A. Analysis on The Presence of MEC}

The results of this step (1A) were already obtained in Anglingkusumo (2005a). Here we summarize them. We showed in Anglingkusumo (2005a) that a trendless long run monetary equilibrium condition can be formed from a vector of three variables $X_{t}=\left(m_{t}-p_{t}, c_{t}\right.$, $R_{t}$ ), using a cointegrated VAR framework allowing for trend breaks in the cointegrating space, i.e. the statistical framework proposed by Johansen et al $(2000)^{11}$. Using quarterly data from Q1/1981 until Q4/2002, we obtained the following VECM system of equations, with a single cointegrating vector [see system of equations (14) in Anglingkusumo (2005a)].

$$
\Delta X_{t}=\mu E_{t} \quad+\sum_{i=1}^{4} \Gamma_{i} \Delta X_{t-i} \quad+\quad \alpha \quad[\beta \gamma], \quad X_{t-1}
$$

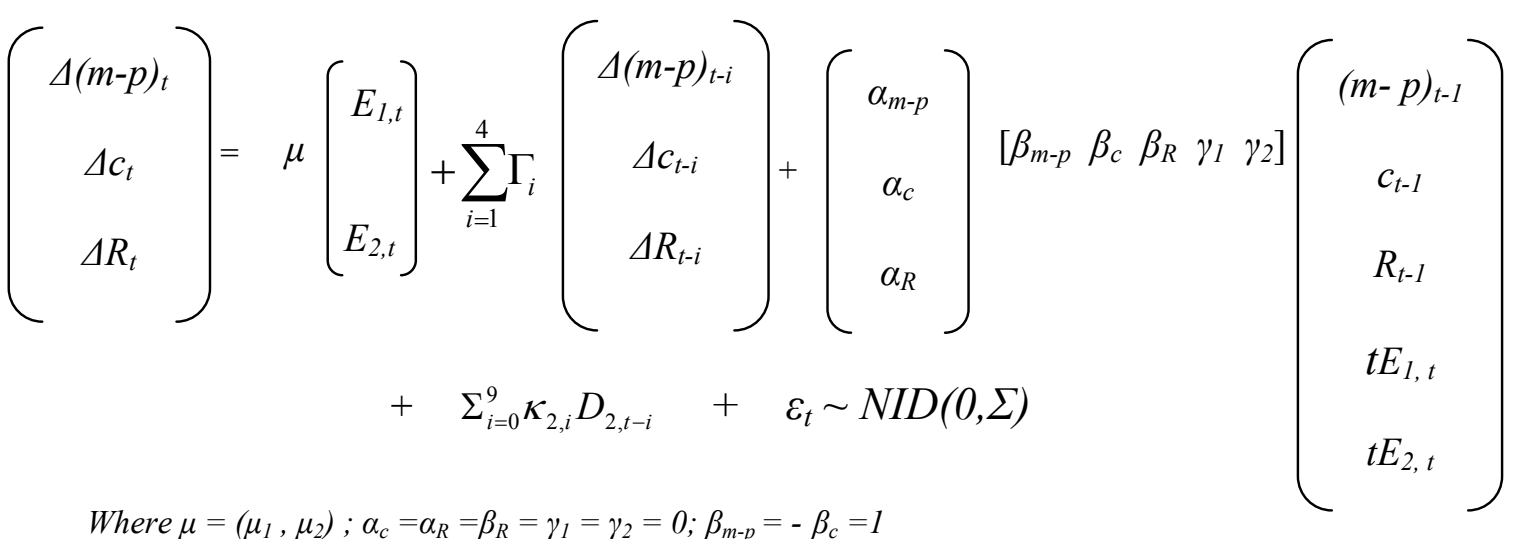

$$
\begin{aligned}
& \text { Sample: } Q 2 / 1982-Q 4 / 2002, t=1, \ldots ., T=83 \text {, and } T_{1}=63
\end{aligned}
$$

In the system of equatins (13) above, $D_{2, t-i}$ are $[0,1]$ indicator dummies that were placed in the VECM system to represent the monetary crisis observations, and $i=0 \ldots 9$. The timing of the crisis period was assumed to be known, covering the period between Q4/1997 and Q1/2000, hence $D_{2, t}$ is placed at Q4/1997 and $D_{2, t-9}$ is at Q1/2000. This period marks the monetary crisis in Indonesia during the Asian crisis and the period of stabilization attempts, jointly pursued by the IMF and the Government of Indonesia. The lag length in VAR is equal to 5. $\mu$ is the vector of estimated intercepts in the two sub-periods, i.e. $\mu_{1} E_{1, t}$ is the pre-crisis intercept and $\mu_{2} E_{2, t}$ is the post crisis intercept. Meanwhile $t E_{1, t}$ and $t E_{2, t}$ are the pre and post crisis trends in the cointegrating vector $[\beta \gamma]$ ' which are tested for a zero coefficient. The pre crisis level dummy is unity before Q4/1997 and zero otherwise. The post crisis level dummy

${ }^{11} R_{t}$ is the nominal interest rate on the 1 -month time deposits in ommercial banks. This variable was included in Anglingkusumo (2005a) because that study was on the stability of the demand for real M1 in pre and post crisis Indonesia. 
is unity after Q1/2000 and zero otherwise. Multiplying these dummies with a trend component, we get $t E_{1, t}$ and $t E_{2, t} . \Gamma_{i}$ are the matrices of short run adjustment coefficients. $\alpha$ is the vector of long run adjustment coefficients, consisting of $\alpha_{m-p}, \alpha_{c}$, and $\alpha_{R}$ which capture the long run feed-back effects on $m_{t}-p_{t}, c_{t}$, and $R_{t}$ respectively. $[\beta \gamma]$ ' is the cointegrating vector consisting of $\beta_{m-p}, \beta_{c}, \beta_{R}, \gamma_{1}$ and $\gamma_{2}$ which are the long run coefficients of $m_{t}-p_{t}, c_{t}$, $R_{t}$, and two sub-period trend components, i.e. $t E_{1, t}$ and $t E_{2, t}$.

The above system of equations (13) states that the vector $X_{t}=\left(m_{t}-p_{t}, c_{t}, R_{t}\right)$ contains a trendless $C I(1,1)_{r=1}$ relationship for the two sub-periods, i.e. the pre and post crisis period. This is because $\gamma_{1}$ and $\gamma_{2}$ are set to zero, given $\beta_{m-p}=1$ as an identifying restriction. Moreover, since the long run adjustment coefficients of $c_{t}$ and $R_{t}$ are restricted to zero given $\gamma_{1}=\gamma_{2}=0$ and $\beta_{m-p}=1$, then $c_{t}$ and $R_{t}$ are weakly exogeneous variables for the estimation of $[\beta \gamma]$ '. Since $\beta_{R}$ is also restricted to zero, the long run stochastic trend of $m_{t}-p_{\mathrm{t}}$ is collinear with the trend in $c_{t}$. In other words, $m_{t}-p_{t}$ and $c_{t}$ share a common trend. Meanwhile, the trend component of $R_{t}$ does not matter in the long run. These results in Anglingkusumo (2005a) confirm requirements $\mathrm{H} 1 \mathrm{C}$ and $\mathrm{H} 2$.

The results above allow us to identify the following form of the empirical long run monetary equilibrium (MĒC):

$$
m_{t}-p_{t}=c_{t}+\zeta_{t} ; \zeta_{t}=I(0)
$$

We normalize this long run relationship so that $\mu=0$ by taking the sample average of the stationary $I(0)$ disequilibria (i.e. $\zeta_{\mathrm{t}}$ ). Our calculation in Anglingkusumo (2005a) yields an average of - 4.74. Denoting this average estimate as $\hat{v}_{0}$ and normalizing (MËC-1) on $\hat{v_{0}}$ we arrive at the following form of the estimated MEC which is equivalent to equation (4) with $\eta_{I}$ $=1$ and $\eta_{0}=-\hat{v_{0}}$ :

$$
m_{t}-p_{t}=-\hat{v_{0}}+c_{t}+\omega_{t} ; \omega_{t}=I(0) ; \hat{v_{0}}=-4.74
$$

$(M \bar{E} C-2)$

This result however, rests on the assumption that the money-output relationship is long run homogenous in prices. In Anglingkusumo (2005a) we found confirmation that there is a long run homogenous relation between money and price levels and that the price levels are endogenous in the nominal M1 demand system. Therefore, a reparameterization into an equation for real M1 balances is both plausible and necessary. This leads us to confirm requirements $\mathrm{H} 1 \mathrm{~A}$ and $\mathrm{H} 1 \mathrm{~B}$.

In addition to the existence of MĒC-2, the unitary elasticity of $m_{t}-p_{t}$ with respect to $c_{t}$ provides a confirmation of the non-declining (constant) equilibrium velocity. This equilibrium velocity, $v^{*}$, is equal to the negative of $\hat{v_{0}}$. Hence, using $v^{*}=-\hat{v}_{0}=4.74$, the equilibrium price level, $p^{*}$, can be directly obtained using equation (2) such that: $p^{*}{ }_{t}=m_{t}-c_{t}+4.74$. This also defines $p^{*}{ }_{t}$ as the excess nominal money stock above the need for real transactions (= "excess money"). Time series plots of $p_{t}$ and $p^{*}{ }_{t}$ are provided in Figure 3. This figure clearly indicates the cointegration of $p_{t}$ and $p^{*}{ }_{t}$. The measure of 
equilibrium price or "excess money" enables us to continue our analysis on the vector $Z_{t}=$ $\left[p_{t}, p_{t}^{*}\right]$, in Step 1B, where we investigate requirements $\mathrm{H} 3$ and $\mathrm{H} 4$.

Figure 3. $p_{t}$ and $p_{t}^{*}$

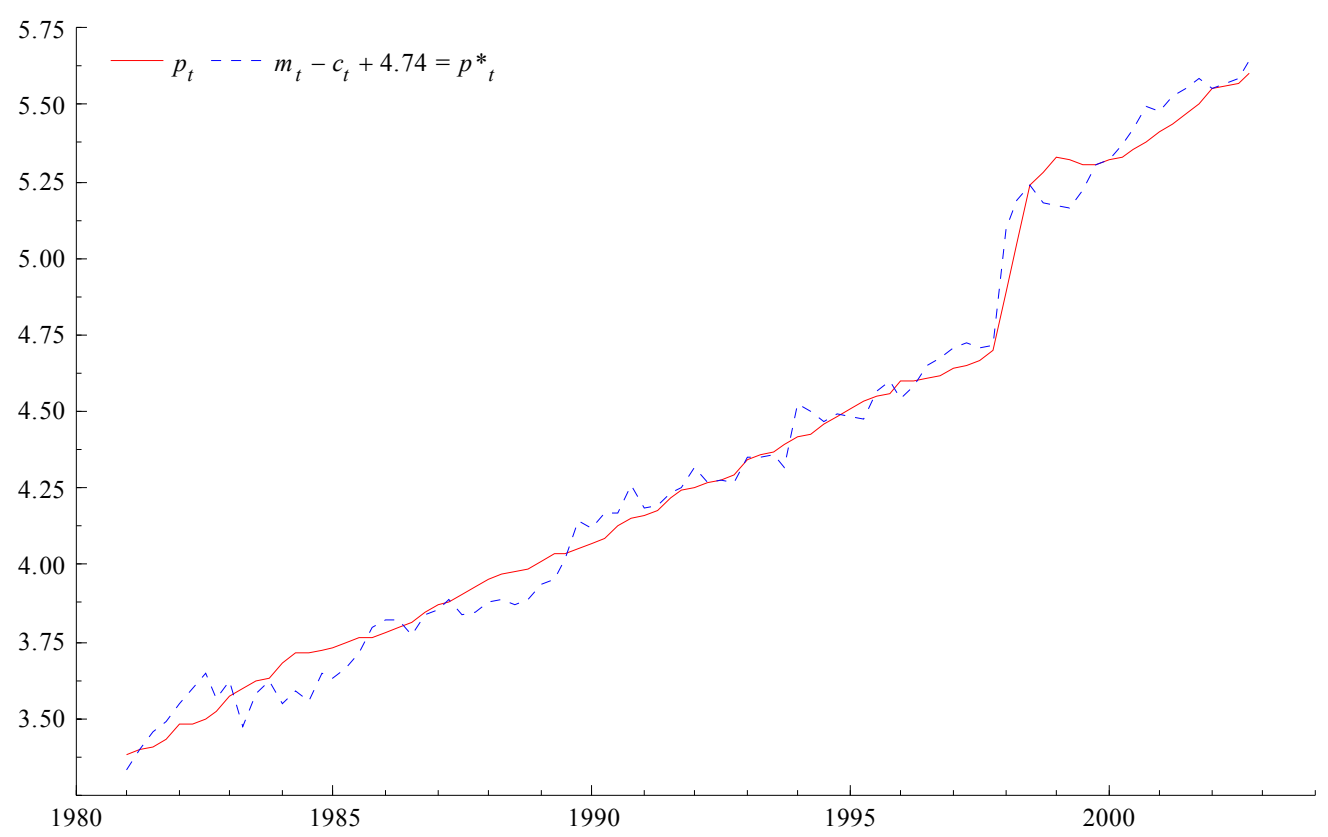

Note: see equation $(M \bar{E} C-2)$.

\section{Step 1B. The Analysis of the Vector $Z_{t}=\left[p_{t}, p_{t}^{*}\right]$}

This step extends the analysis in Anglingkusumo (2005a). As in Step 1A, the cointegration test on vector $Z_{t}=\left[p_{t}, p_{t}^{*}\right]$ follows the framework of Johansen et al (2000), illustrated in Anglingkusumo (2005a). Similar set ups for indicator dummies and sub-sample intercepts and trends are used as in system of equations (14) in Anglingkusumo (2005a). The results are presented in Table 1 and system of equations (14) below. The diagnostic tests of the VECM using lag length 4 reveal residuals that are relatively clean from serial correlation (Vector AR 1-5 test: $\mathrm{F}(20,100) / p$-value $=1.51 / 0.094)$ and heteroskedasticity (Vector heteroskedasticity test: $\mathrm{F}(66,114) / p$-value $=0.82 / 0.793)$. Despite the presence of non-Gaussian residuals (Vector normality test: $\chi^{2}(4) / p$-value $=12.31 / 0.015$ ), we take the VECM with $p=5$ and $k=p-1=4$ as the multivariate representation of the data generating process. The cointegration test for $r=0$ points to a trace statistic of 32.316 which is significant at $10 \%$, meanwhile for $r=1$ the trace statistic is insignificant. This does not contradict $r=1$. Hence, $p_{t}$ and $p^{*}{ }_{t}$ in $Z_{t}=\left[p_{t}, p^{*}{ }_{t}\right]$ can be considered $C I(1,1)_{r=1}$.

The normalized cointegration relationship with the long run coefficient of $p_{t}$, i.e. $\beta_{p}$, set to 1 , suggests a long run relationship that is theoretically quite plausible in representing a closely knitted money-inflation nexus. This is so because the long run coefficient of $p_{t}^{*}$, i.e. $\beta_{p^{*}}$, is close to -1 , and the long run coefficients of the trends in the two sub-periods, i.e. $\gamma_{1}$ (pre-crisis trend) and $\gamma_{2}$ (post crisis trend), are close to 0, see Panel B in Table 1. We proceed 
with assessing several restrictions on the matrix $\Pi=\alpha[\beta \gamma]^{\prime}$ to examine such conjectures. The results are reported in Panels C-E of Table 1.

Table 1. Long Run Analysis on Vector $Z_{t}=\left(p_{t}, p^{*}\right)$ (sample Q1/1982-Q4/2002)

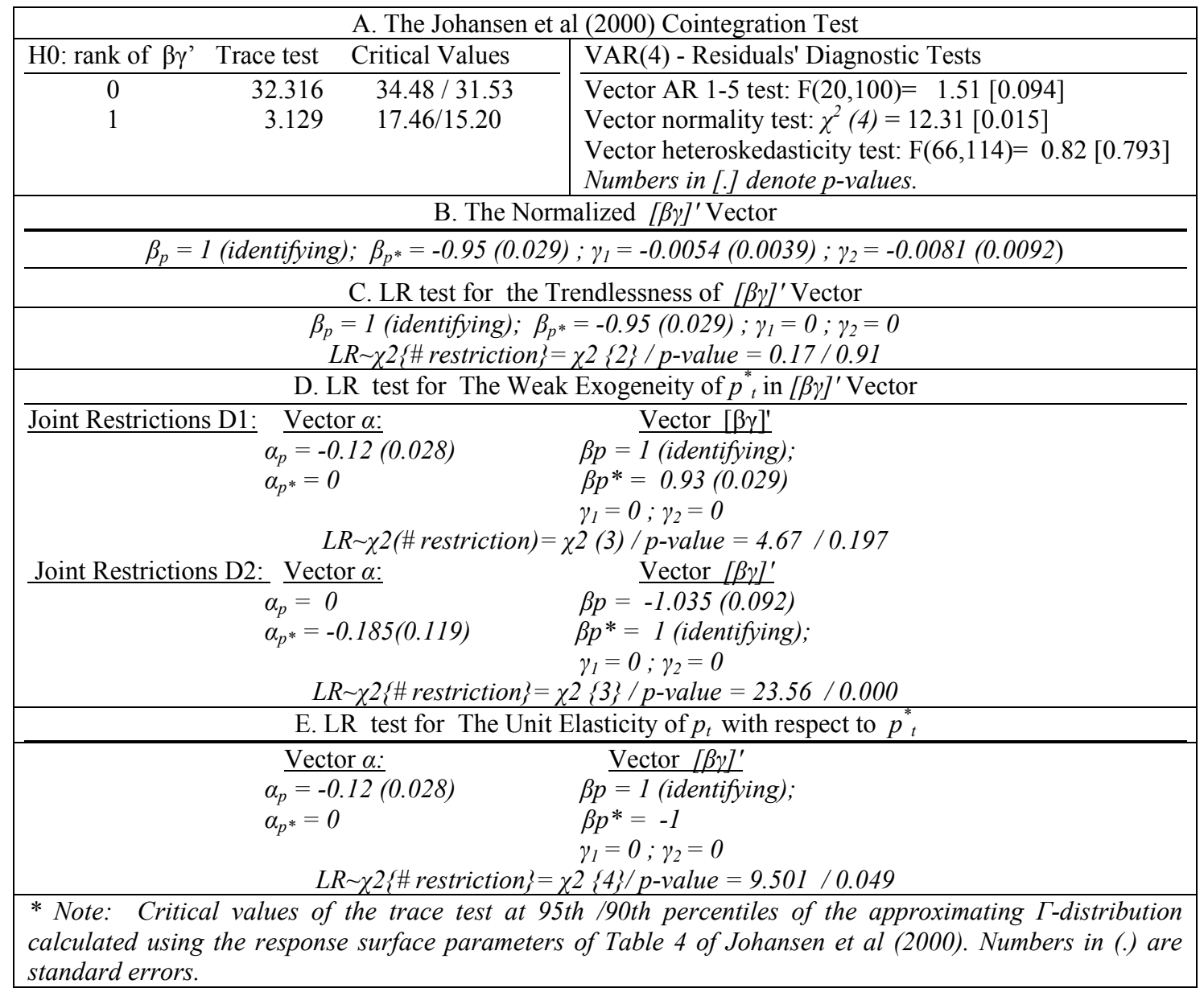

The restrictions in Panel $\mathrm{C}$ imply a trendless long run relationship in the vector $Z_{t} \sim$ $C I(1,1)_{r=1}$, i.e. $\gamma_{1}=\gamma_{2}=0$ given $\beta_{p}=1$ as the identifying restriction in $[\beta \gamma]^{\prime}$. The test result is a $p$-value of 0.91 confirming the absence of a trend in the two sub-periods. This again implies that the long run relationship between the two sub-periods does not suffer from a trend break. Next, in Panel D we test two multiple restrictions, i.e. D1 and D2. Restrictions D1 imply the validity of identifying the long run relationship in terms of $p_{t}$ where $p_{t}{ }_{t}$ serves as a weakly exogenous variable for the estimation of the cointegrating vector, i.e. $\beta_{p}=1$ with $\alpha_{p^{*}}=0$ in the equation for $\Delta p^{*}{ }_{t}$, given $\gamma_{1}=\gamma_{2}=0$. The result is a $p$-value of 0.197 but the coefficient of $\alpha_{p^{*}}$ is not close to zero, as seen in the results for D2. The joint restrictions D2 reverse the identifying restriction to $\beta_{p^{*}}=1$, and test for the weak exogeneity of $p_{t}$ in the estimation of the cointegrating vector i.e. $\alpha_{p}=0$ in the equation for $\Delta p_{t}$, given $\gamma_{1}=\gamma_{2}=0$. The test has a $p$-value of 0.000 indicating invalid restrictions. The results in Panel D confirm a trendless long run price equation that is conditional on excess money. Hence requirements $\mathrm{H} 3$ and $\mathrm{H} 4$ are fulfilled empirically. Finally, the restrictions in Panel E imply a unitary 
elasticity of $p_{t}$ to excess money, given the joint restrictions D1. The test results is a $p$-value of 0.049. This suggests that the unitary elasticity of $p_{t}$ to excess money is not easily accepted. However, the reported long run coefficient of excess money in restrictions D1 is very close to 1 at 0.93 . Therefore at this stage we impose the additional long run restriction, namely the long run elasticity of $p_{t}$ with respect to excess money is equal to 1 .

$$
\Delta Z_{t}=\mu E_{t} \quad+\sum_{i=1}^{4} \Gamma_{i} \Delta Z_{t-i} \quad+\quad \alpha \quad[\beta \gamma], \quad X_{t-1}
$$

$$
\begin{gathered}
\left(\begin{array}{c}
\Delta p_{t} \\
\Delta p_{t}^{*}
\end{array}\right)=\mu\left(\begin{array}{c}
E_{1, t} \\
E_{2, t}
\end{array}\right)+\sum_{i=1}^{4} \Gamma_{i}\left(\begin{array}{c}
\Delta p_{t-i} \\
\Delta p^{*}{ }_{t-i}
\end{array}\right)+\left(\begin{array}{c}
\alpha_{p} \\
\alpha_{p^{*}}
\end{array}\right)\left(\begin{array}{lll}
\beta_{p} \beta_{p^{*}} & \gamma_{1} & \gamma_{2}
\end{array}\right] \\
+\Sigma_{i=0}^{9} \kappa_{2, i} D_{2, t-i}+\varepsilon_{t} \sim N I D(0, \Sigma)
\end{gathered}
$$

Where $\mu=\left(\mu_{1}, \mu_{2}\right) ; \alpha_{p^{*}}=\gamma_{1}=\gamma_{2}=0 ; \beta_{p}=-\beta_{p^{*}}=1$

Sample: $Q 1 / 1982-Q 4 / 2002, t=1, \ldots, T=84$, and $T_{1}=64$

Based upon restrictions D1 and an additional restriction that $\beta_{p^{*}}=-1$ in $[\beta \gamma]$ ', we have identified the VECM for $Z_{t}=\left(p_{t}, p_{t}{ }_{t}\right)$ represented by system of equations (14). This system of equations simply states that the long run stochastic trend of $p_{t}$ is collinear with the trend in excess money. A recursive plot of the test statistics for restrictions D1 with an additional restriction that $\beta_{p^{*}}=-1$ in $[\beta \gamma]$ ' illustrates the stability of such long run restrictions, see Figure 4a. It is shown that except for a brief episode in post crisis period, the restrictions hold recursively at $10 \%$. Figure $4 \mathrm{~b}$ plots the long run cointegrating relationship given restrictions D1 and the extra restriction that the elasticity of $p_{t}$ with respect to excess money is equal to unity. 
Figure 4a. Recursive plot of the LR-Test on joint restrictions D1 and $\beta_{p^{*}}=-1$ imposed (Initialization $=24$ Quarters)

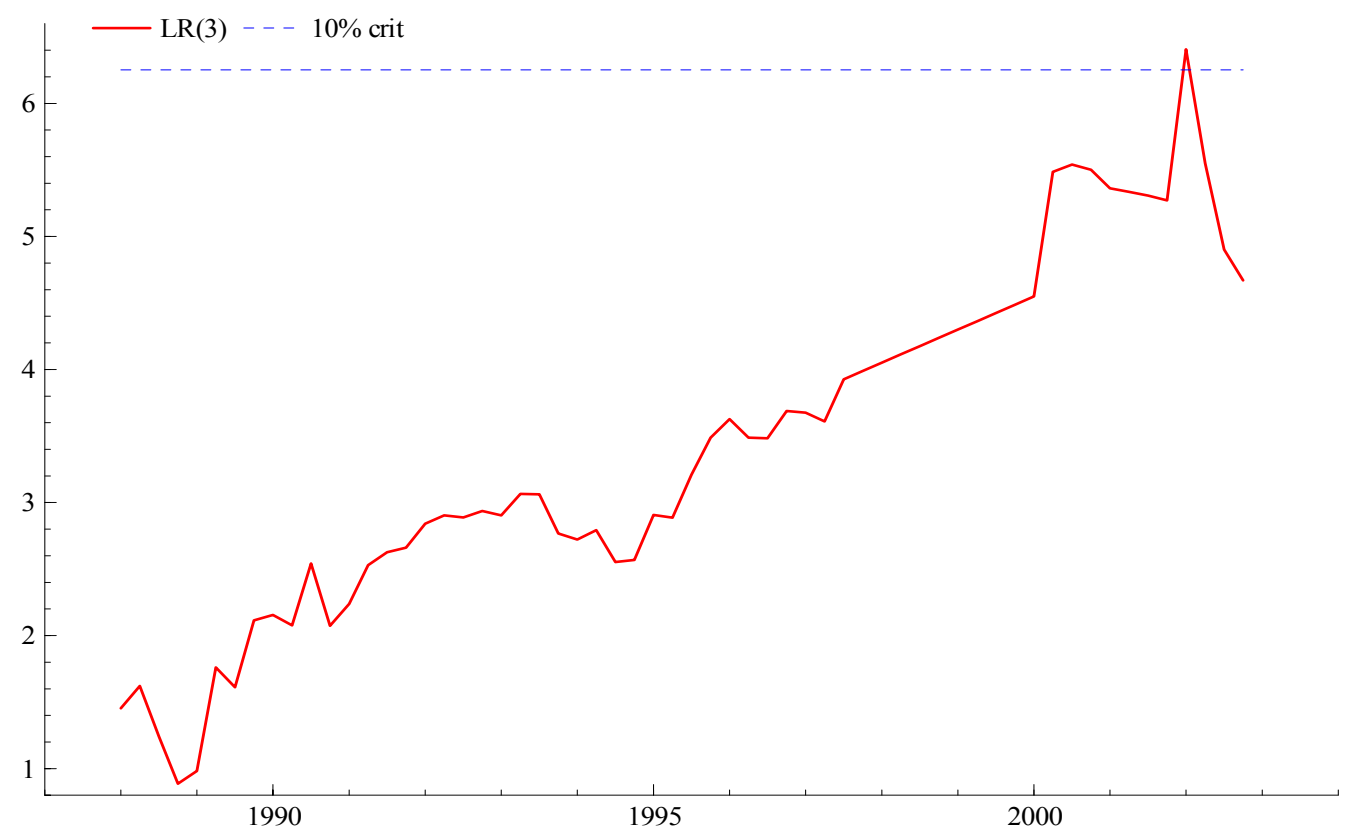

Figure 4b. Plot of $p_{t}-p_{t}^{*}=C I(1,1)_{r=1}$, with joint restrictions D1 and $\beta_{p^{*}}=-1$ imposed

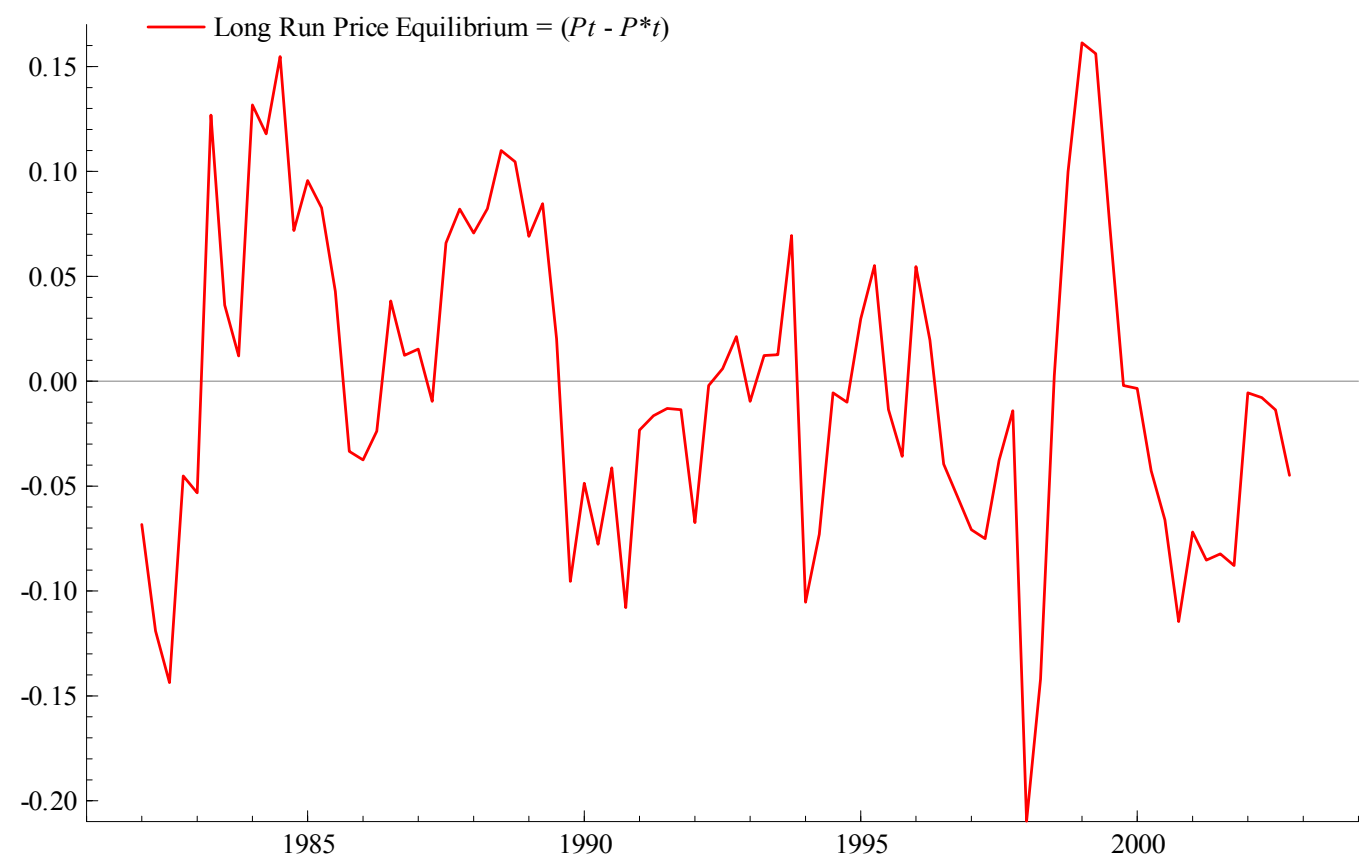




\section{Step 2. The MS-ECM Analysis}

The parsimonious specification in terms of $p_{t}$ and $p^{*}{ }_{t}$ allows us to investigate simple non-linear Markov-Switching models, instead of using many dummy variables. Our MSECM analysis focuses on estimating the single P-star equation for inflation (3) in section 2 using specification (12b) in sub-section 3.1. To avoid modeling a non-linear equation that is too complex, we limit the analysis only to 2 regimes with 1 period lag in ECM. This is denoted as MS(2)-ECM(1) and used to estimate specification (12b). Our aim is to identify the low and high regime in $\Delta p_{t}$, where the high regime should correspond to the Asian monetary crisis period in Indonesia. The ML estimation is conducted using the EM algorithms implemented by Krolzig (1998). Three non-linear variants of equation (3) are estimated using specification (12b). The results are reported in Table 2. Model 1 is the non-linear estimate of equation (3) using specification (12b) with all the short run adjustment variables. Model 2 is the non linear estimate of equation 3 using specification (12b) but omitting the $\Delta p_{t-1}^{*}$ variable, meanwhile Model 3 omits both $\Delta p_{t-1}$ and $\Delta p_{t-1}^{*}$ variables.

It can be seen in Table 2 that the three models are in agreement regarding the starting date of the Asian monetary crisis, namely Q1/1998. The ending date of the monetary crisis (regime 2), which corresponds to the end of the stabilization period and marks the beginning of the post crisis era, is not uniform across models. The earliest estimate comes from Model 2, i.e. in Q3/1999, followed by Model 1 in Q4/1999, and lastly Model 3 in Q1/2000. Thus, the duration of the monetary crisis and its stabilization period range from $6-8$ quarters and the post crisis era starts roughly between Q3/1999 and Q1/2000. These three different monetary crisis periods lead us to question the validity of the analyses in Step 1B of the 2 step procedures that we reported earlier in this section. Due to the method proposed by Johansen et al (2000), in those analyses the period between Q4/1997 and Q1/2000 was treated as the period of monetary crisis in Indonesia. Re-analyzing Step 1B using the crisis period from Model 3 yields no significant departure from the results obtained above. However, when the estimated break periods from Model 1 or 2 are used, the results change significantly. The restrictions D1 in Table 1 are no longer valid with a $p$-value of 0.000 and the recursive LR analysis shows a significant permanent jump above the $10 \%$ threshold in the post crisis era. These results suggest that an end of crisis date earlier than Q1/2000 causes the VAR model for vector $Z_{t}=\left(p_{t}, p^{*}{ }_{t}\right)$ in Step $1 \mathrm{~B}$ to be mis-specified. With such an ending date, the $(0,1)$ indicator dummies in system of equations (14) will be mis-specified, and the salient features of the data will be missed. Therefore, we argue that the longer estimated monetary crisis break period obtained from Model 3 is our best estimate from the non-linear modeling of $\Delta p_{t}$, although it does not seem to fit the crisis data as well as the other models. 
Table 2. The Results of the MS (2) - ECM (1) Estimation of Specification (12b) (Sample : Q1/1982 - Q4/2002), Dependent variable : $\Delta p_{t}$

\begin{tabular}{|c|c|c|c|}
\hline Coefficients & Model 1 & Model 2 & Model 3 \\
\hline Regime 1: $\mu_{l}$ & $0.022(0.002 / 8.179)$ & $0.018(0.002$ / 6.97) & $0.02(0.001 / 14.716)$ \\
\hline$\Delta p_{t-1}$ & $-0.005(0.105 /-0.047)$ & $0.084(0.118 / 0.712)$ & ---- \\
\hline$\Delta p_{t-1}^{*}$ & $-0.083(0.027 /-3.075)$ & ---- & ---- \\
\hline$\left(p-p^{*}\right)_{t-1}$ & $-0.079(0.027 /-2.942)$ & $-0.065(0.02 /-3.196)$ & $-0.048(0.021 /-2.279)$ \\
\hline Dates of Regime 1 & $\begin{array}{l}Q 2 / 1982-Q 4 / 1997 \\
Q 4 / 1999-Q 4 / 2002\end{array}$ & $\begin{array}{l}Q 2 / 1982-Q 4 / 1997 \\
Q 3 / 1999-Q 4 / 2002\end{array}$ & $\begin{array}{l}Q 2 / 1982-Q 4 / 1997 \\
Q 1 / 2000-Q 4 / 2002\end{array}$ \\
\hline $\begin{array}{c}\text { Regime 2: } \mu_{2} \\
\Delta p_{t-1} \\
\Delta p_{t-1}^{*} \\
\left(p-p^{*}\right)_{t-1}\end{array}$ & $\begin{array}{c}0.177(0.0158 / 11.190) \\
-0.637(0.141 /-4.494) \\
-0.343(0.074 /-4.586) \\
-1.110(0.092 /-12.065)\end{array}$ & $\begin{array}{c}0.18(0.027 / 6.64) \\
-0.787(0.226 /-3.472) \\
-\overline{-}- \\
-0.768(0.137 /-5.579)\end{array}$ & $\begin{array}{c}0.084(0.017 / 4.957) \\
--- \\
--- \\
-0.532(0.123 /-4.313)\end{array}$ \\
\hline Dates of Regime 2 & $\begin{array}{c}Q 1 / 1982 * * \\
Q 1 / 1998-Q 3 / 1999\end{array}$ & $\begin{array}{c}Q 1 / 1982 * * \\
Q 1 / 1998-Q 2 / 1999\end{array}$ & $\begin{array}{c}Q 1 / 1982 * * \\
Q 1 / 1998-Q 4 / 1999\end{array}$ \\
\hline $\begin{array}{l}\text { Standard Error Regime } 1 \\
\text { Standard Error Regime } 2\end{array}$ & $\begin{array}{l}0.0112 \\
0.0137\end{array}$ & $\begin{array}{l}0.0123 \\
0.0235\end{array}$ & $\begin{array}{l}0.0116 \\
0.0429\end{array}$ \\
\hline
\end{tabular}

Notes: Numbers in (./.) are standard errors / t-statistics. Dates of each regime are selected based on the estimated filtered regime probabilities, using cut-off value Prob. $>0.5$, probability of a regime change below this cut-off value is assumed to equal 0. Regime 1 is the low inflation regime, and regime 2 is the high inflation regime (crisis regime). **denotes 1 outlier observation in the early year of the sample that is categorized as regime 2 by the MS-ECM estimation with Prob. $=0.6$

In Model 3, the process of $\Delta p_{t}$ is determined by random switches in the intercept and in the long run price adjustment to sweep away any deviation in the price level that is below or above equilibrium price. During the tranquil period (regime 1), the long run price adjustment coefficient is quite low, suggesting a slow process of equilibrium correction. Hence, the impact of the changes in excess money on inflation will not be immediate and instead will be characterized by long delays. This finding lends support to the assertion that during the tranquil period when expectations are relatively stable, the cost of being off equilibrium is low, and hence monetary disturbances should not haphazardly affect price development. Meanwhile, during the turbulent period (regime 2) the long run price adjustment coefficient is quite high at -0.532 , suggesting rapid equilibrium correction in the event of monetary disturbances. This effect is even stronger in Models 1 and 2. Note that the adjustment coefficient estimated in Table 1 Panel D (Joint Restrictions D1) is much closer to the regime 1 than to regime 2 estimates in Table 2.

\subsection{An Annual Inflation Model}

To supplement our analysis we conduct inflation modeling in annual changes, i.e. in $\Delta_{4} p_{t}$. We use the estimated regime periods from Model 3 to identify the monetary crisis break, namely we place $(0,1)$ dummies for the period Q1/1998 - Q4/1999. We use lag 5 for the equilibrium correction variable, i.e. $\left(p-p^{*}\right)_{t-5}$ instead of $\left(p-p^{*}\right)_{t-1}$. Employing the general to specific modeling technique we arrive at the specification for $\Delta_{4} p_{t}$ reported in equation (15). The diagnostic tests of the residuals point to homoskedasticity with no-serial correlation. The Ramsey-RESET test suggests linearity of the relationship. 


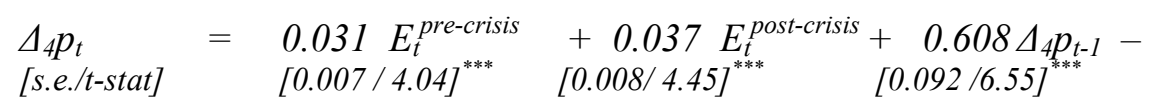

$$
\begin{aligned}
& \begin{aligned}
- & 0.088\left[p_{t-5}-p^{*}{ }_{t-5}-0\left(t E_{t}{ }^{\text {pre-crisis }}+t E_{t}{ }^{\text {post-crisis }}\right)\right] \\
& {[0.034 /-2.56]^{*} }
\end{aligned}
\end{aligned}
$$

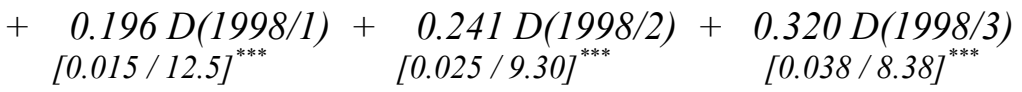

$$
\begin{aligned}
& +0.23 D(1998 / 4)+0.086 D(1999 / 1)-0.016 D(1999 / 2) \\
& {[0.053 / 4.26]^{* * *} \quad[0.05 / 1.55] \quad[0.038 /-0.41]} \\
& \text { - } 0.116 D(1999 / 3)-0.016 D(1999 / 4)+\varepsilon_{t}
\end{aligned}
$$

Effective Sample: Q2/1982-Q4/2002

$R^{2}=0.98$

AR 1-5 test: $F / p$-value $=2.329(0.052)$

$R S S=0.015$, S.E. $=0.014$

ARCH 1-4 test $: F / p$-value $=0.566(0.688)$

RESET test: $F / p$-value $=0.31$ (0.57) Heteroskedasticity test: $F / p$-value $=0.972(0.489)$

Notes: $E_{t}$ and $t E_{t}$ are the sub-sample intercepts and trends. Ds are the $[0,1]$ indicator dummies. ${ }^{* * *}, * *$, and $*$ indicate significance at $1 \%, 5 \%$, and $10 \%$.

In specification (15), annual inflation is strongly determined in the short run by its own 1 period lag. This might suggest that agents' adaptive inflation expectations are quite forceful, but Table 2 indicated otherwise. While $\Delta_{4} p_{t}$ and $\Delta_{4} p_{t-1}$ have a strong correlation in (15), $\Delta p_{t}$ is close to white noise in the results reported in Table 2. Hence, the high coefficient of $\Delta_{4} p_{t-1}$ is a consequence of the data transformation. In the long run, inflation is determined by a long run adjustment of prices to correct any disequilibrium induced by changes in excess money (equilibrium price) with a coefficient of -0.083 . This low adjustment coefficient confirms earlier findings that inflation is a monetary phenomenon only after some long delays. To get some perspective on the stability of specification (15) look at Figure 5 where we provide the plots of the coefficients of $\Delta 4 p_{t-1}$ and $\left[p_{t-5}-p_{t-5}^{*}-0\left(t E_{t}{ }^{\text {pre-crisis }}+t E_{t}{ }^{\text {post }}\right.\right.$ crisis)] estimated recursively with increasing sample size. The error correction coefficient becomes slightly less significant overtime, but retains a negative value, comparable with the regime 1 estimates of the models 1-3 in Table 2. From the plots of the 1 step residuals and Nstep Chow forecast test statistics we learn that specification (15) is a stable function. Moreover, a test of the restriction to see whether the difference between the coefficients $E_{t}^{\text {pre- }}$ ${ }^{c r i s i s}$ and $E_{t}^{\text {post-crisis }}$ equals zero results in a $\chi^{2}(1)$ statistic with a $p$-value $=0.15$ which validates the restriction. This implies a non-breaking relationship between excess money and prices before and after the monetary crisis. Hence, one can also argue for the presence of a cobreaking relationship between excess money and prices in the cointegrating vector, in the sense of Hendry (1997) and Hendry and Mizon (1998); on this last point see also Figure 3.

To conclude our annual inflation analysis, Figure 6 depicts the ex-post historical simulations of $\Delta_{4} p_{t}$ using specification (15). As one can see from the one step residuals in 
Figure 5 and the ex-post historical simulations in Figure 6, this model for $\Delta_{4} p_{t}$ tracks the path of annual inflation in Indonesia before and after the crisis remarkably well.

Figure 5. The Stability of Specification (15)
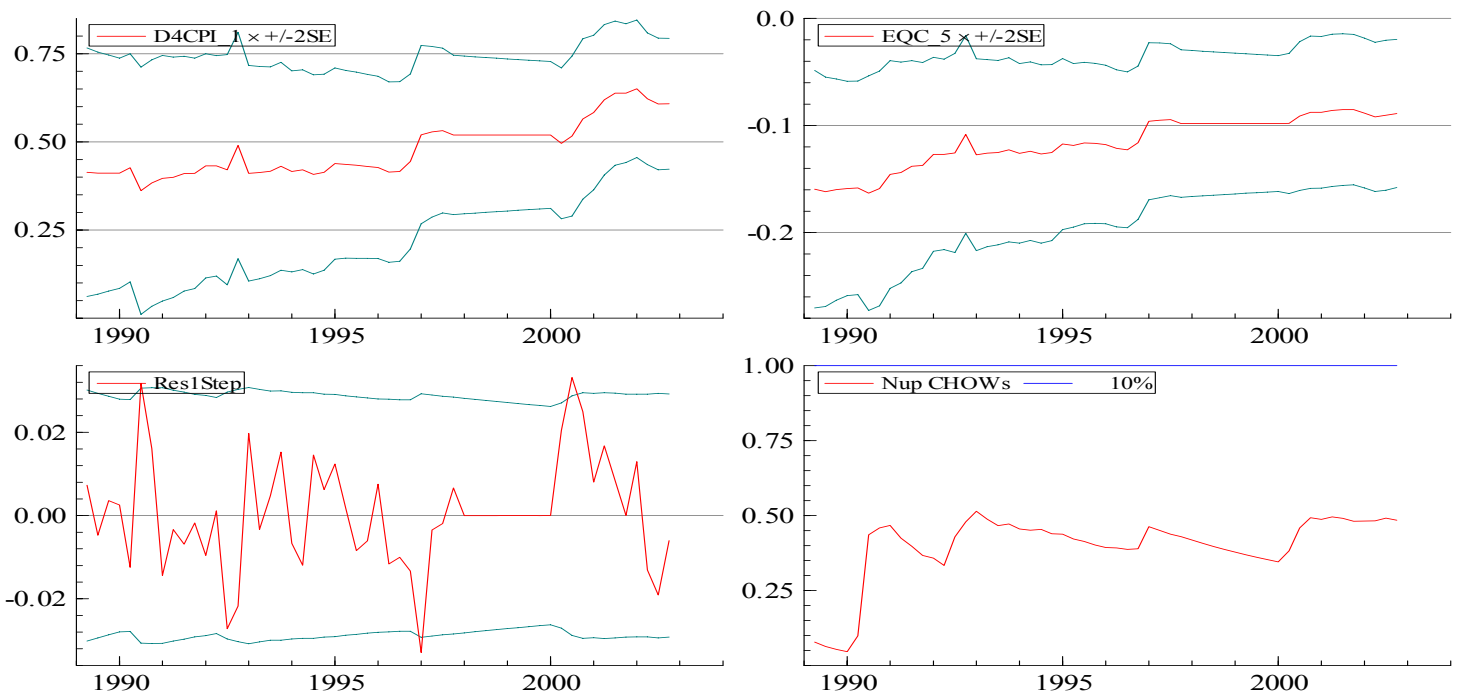

Notes: D4CPI and EQC 5 are the recursive plots of the coefficients of $\Delta_{4} p_{t-1}$ and $\left[p_{t-5}-p_{t-5}-0\left(t E_{t}{ }^{\text {pre-crisis }}+\right.\right.$ $\left.\left.t E_{t}{ }^{\text {post-crisis }}\right)\right]$ in equation (15). Res 1 Step uses the recursive 1 step residuals. Nup CHOWs is N-step Chow forecast test. $10 \%$ is the critical values and S.E. is the standard error. Initialization for the recursive plots is 24 quarters.

Figure 6. Ex-Post Historical Simulations of Specification (15) (Q2/1982 - Q4/2002, x 100 \% p.a.)

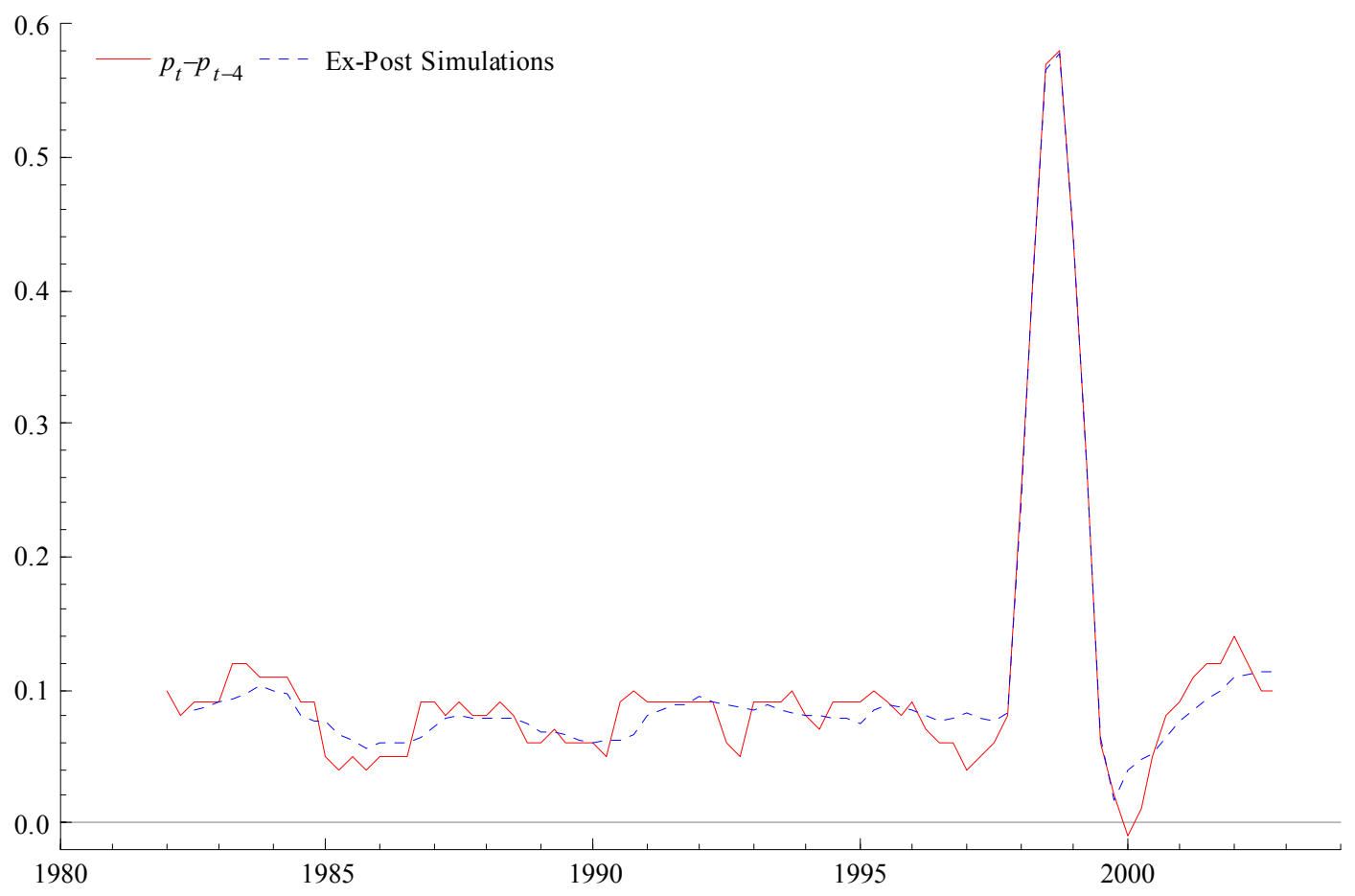




\section{Conclusions}

In this paper we have estimated several P-star models of inflation for Indonesia, which explains inflation by an equilibrium correction model, where long run movements of prices are determined by excess money. We found that a simple Markov-Switching P-star model tracks the behavior of inflation remarkably well since the early 1980s until the end of 2002.

The empirical results show that during the turbulent (monetary crisis) period, the changes in inflation originated mainly from excess money shocks and the price adjustments to eliminate such shocks. Hence, the high inflation during the crisis had a strong monetary explanation.

During the tranquil period, the long run price adjustment is slower to bring prices in line with the changes in excess money. Hence, during the tranquil period when expectations are more stable, money still matters as the prime mover of inflation, yet its role is constrained to the long run.

Finally, there is also evidence that excess money and prices in Indonesia cobreak during the Asian crisis.

\section{References}

Anglingkusumo, R. 2005a. "Stability of the Demand for Real Narrow Money in Indonesia: Evidence from the Pre and Post Crisis Era." Working paper manuscript, available upon request (ranglingkusumo@imf.org).

Boswijk, H. Peter. 1992. "Cointegration, Identification, and Exogeneity: Inference in Structural Error Correction Models." Tinbergen Institute Research Series 37.

Clarida, R.; L. Sarno; M.P. Taylor; G. Valente. 2003. "The out of sample success of term structure models as exchange rate predictors: a step beyond." Journal of International Economics 60, 61-83.

Engle, R.F. and C.W.J. Granger. 1987). "Co-integration and Error Correction: Representation, Estimation, and Testing." Econometrica 55, pp. 251-276.

Ericsson, N. R., D.F. Hendry, and G.E. Mizon. 1998. " Exogeneity, Cointegration, and Economic Policy Analysis." International Finance Discussion Paper 616, Board of Governors of the Federal Reserve System.

Favero, C.A. 2001. Applied Macroeconometrics. Oxford: Oxford University Press.

Gerlach, S. and L.E.O. Svensson. 2003. " Money and Inflation in the Euro Area: A Case for Monetary Indicators." Journal of Monetary Economics, Forthcoming. 
Hallman, J.J.; R.D. Porter; D.H. Small. 1991. "Is the Price Level Tied to the M2 Monetary Aggregate in The Long Run." The American Economic Review 81, p. 841-58

Hamilton J.D. 1989."A New Approach to Economic Analysis of Non-Stationary Time Series and the Business Cycle." Econometrica 57, 357 -384.

Hamilton J.D. 1990. "Analysis of Time Series Subject to Changes in Regime." Journal of Econometrics 45, 39-70.

Harris, R. and R. Sollis. 2003. Applied Time Series Modelling and Forecasting. John Wiley \& Sons Ltd. , England.

Hendry, D.F. 1997. "Econometrics of Macroeconomic Forecasting." Economic Journal 107, September, p. 1330 - 57.

Hendry, D. F., and K. Juselius. 2000. " Explaining Cointegration Analysis: Part II." Discussion Papers 00-20, University of Copenhagen, Institute of Economics.

Hendry, D.F. and G.E. Mizon .1998. " Exogeneity, Causality, and Co-Breaking in Economic Policy Analysis of a Small Econometric Model of Money in the UK." Empirical Economics 23, p. $267-294$.

Herwartz, H. and H.E. Reimers. 2001. " Long Run Link Among Money, Prices, and Output: Worldwide Evidence." Discussion Paper 14/01, Economic Research Center, Deutsche Bundesbank.

Hodrick, Robert, and Edward C. Prescott (1997)."Postwar U.S. Business Cycles: An Empirical Investigation." Journal of Money, Credit, and Banking 29, 1, pp. 1 - 16.

Humphrey, T.M. 1989. "Precursors of the P-Star Model." Federal Reserve Bank of Richmond Economic Review (July / August).

Hutabarat, A.R.; R. Anglingkusumo; F. Madjardi; R. E. Wimanda. 2000. "Policy Rules for Forward Looking Inflation Control." Bulletin Ekonomi Moneter dan Perbankan (3), 3, December, Bank Indonesia.

Johansen, S. 1988. "Statistical Analysis of Cointegration Vectors." Journal of Economic Dynamics and Control 12, 231-254.

Johansen, S. 1991. "Estimation and Hypothesis Testing of Cointegration Vectors in Gaussian VAR.” Econometrica 59, 1551-1580.

Johansen, S. 1992."Testing Weak Exogeneity and the Order of Cointegration in UK Money Demand Data." Journal of Policy Modelling 14, p. 313-334.

Johansen, S. 1995. Likelihood-Based Inference in Cointegrated VAR Models. Oxford: Oxford University Press. 
Johansen, S. , Mosconi, R., and Nielsen, B. 2000. "Cointegration Analysis in the Presence of Structural Breaks in the Deterministic Trend.” Econometrics Journal 3, p. 216-249.

Kool, C. and J.A. Tatom. 1994. "The P-Star Model in Five Small Economies." The Federal Reserve Bank of St. Louis.

Krolzig, H.M. 1996. "Statistical Analysis of Cointegrated VAR Process with Markovian Regime Shifts." Sfb 373 Discussion Paper 25/1996.

Krolzig, H.M. 1997. Markov Switching VAR: Modelling, Statistical Inference, and Application to Business Cycle Analysis. Berlin, Springer.

Krolzig, H.M. 1998. "Econometric Modelling of Markov Switching VAR Using MSVAR for Ox." Discussion Paper, Department of Economics, University of Oxford: http://www.economics.ox.ac.uk/hendry/krolzig.

Krolzig, H.-M.; M. Marcellino; G. E. Mizon. 2002. "A Markov-switching Vector Equilibrium Correction Model of the UK Labour Market." Empirical Economics 27, 233254.

McLeod, R. 1997. "Explaining Chronic Inflation in Indonesia." Journal of Development Studies 33 (3).

McLeod, R. 2002. "Is Bank Indonesia the Cause of Inflation." mimeo, RSPAS, ANU, Canberra.

McLeod, R. 2003. Towards Improved Monetary Policy in Indonesia. Bulletin of Indonesian Economic Studies (39), 3, December: Indonesia Project - Australian National University.

Nachane D.M. and R. Lakhsmi. 2002. "Dynamics of Inflation in India : a P-Star Approach." Applied Economics 34, 101-110.

Sarno, L.; D. L. Thornton; G. Valente. 2002. "Federal Funds Rate Prediction." Working Paper, No. 2002-005B, Federal Reserve Bank of St. Louis.

Taylor, J. B. 2000. Summary Remarks at Bank Indonesia. Conference on "Inflation Targeting and Monetary Policies in Emerging Economies" at the Central Bank of the Republic of Indonesia, Jakarta, Indonesia, July13-14.

Tillman, P. 2003."Cointegration and Regime-Switching Risk Premia in the U.S. Term Structure of Interest Rates." Bonn Graduate School of Economics, Discussion Paper 27 / 2003.

Trecroci, C. and J.L. Vega. 2000). "The Information Content of M3 for Future Inflation." ECB Working Paper No. 33. 